\title{
Challenges and opportunities of using tele-nursing during COVID-19 pandemic: An integrative review
}

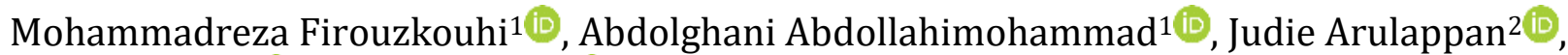 \\ Taha Nouraei ${ }^{3}$ (D) Jebraeil Farzi $^{4 *(1)}$
} ${ }^{1}$ Associate Professor, Department of Medical Surgical, Faculty of Nursing and Midwifery, Zabol University of Medical Sciences, Zabol, Iran
2 Department of Maternal and Child Health Nursing, College of Nursing, Sultan Qaboos University, Muscat, Sultanate of Oman
${ }^{3}$ BSC and Former MSC Student in Orthosis and Prosthesis, DDS Student, Dentistry School, Ilam University of Medical Sciences, Ilam, Iran
${ }^{4}$ Assistant Professor, Department of Health Information Technology, School of Allied Medical Sciences, Zabol University of Medical Sciences,
Zabol, Iran

\begin{tabular}{ll}
\hline Article Info & A B S T R A C T \\
\hline $\begin{array}{l}\text { Article type: } \\
\text { Review }\end{array}$ & Introduction: Telenursing during the COVID-19 pandemic with an \\
& emphasis on self-care is an effective approach to help patients, hospitals, as \\
& well as community. Despite the many challenges and benefits, tele-nursing \\
Article History: & can be used to help COVID 19 patients with new technologies. This study \\
Received: $2021-09-17$ & aimed to explore the challenges and opportunities of using tele-nursing in \\
Accepted: $2021-11-08$ & the COVID 19 Pandemic for helping patients with COVID 19 to gain better \\
Published: $2021-12-13$ & care.
\end{tabular}

*Corresponding author:
Jebraeil Farzi
Assistant Professor, Department of
Health Information Technology,
School of Allied Medical Sciences,
Zabol University of Medical Sciences,
Zabol, Iran

Email:j-farzi@alumnus.tums.ac.ir

\section{Keywords: \\ COVID-19 \\ Coronavirus \\ Telenursing \\ Nurse Roles \\ Internet}

Material and Methods: An integrative review was conducted from December, 2019 to January, 2021. Databases of PubMed, MEDLINE, Web of Science, Scopus, CINHAL, and google scholar were searched on the concept of tele-nursing by using the following keywords, of COVID-19, Coronavirus, Telenursing, nurse roles, technology, Pandemics and Internet. DaA ta were analyzed according to Broome method.

Results: The main results of tele-nursing in COVID 19 includes: implementation problems, insurance coverage, prevention of nurses, the problem of continuing care, and changing the roles of nurses' infections, development of nursing knowledge, the emergence of technological care providing, emphasis on patient independence and transmission cycle control.

Conclusion: Tele-nursing, this, despite the challenges, has many benefits that are effective in the current situation and effective, and reliable measure, through effective planning and implementation, help control COVID-19.

Cite this paper as:

Firouzkouhi M, Abdollahimohammad A, Arulappan J, Nouraei T, Farzi J. Challenges and opportunities of using tele-nursing during COVID-19 pandemic: An integrative review. Front Health Inform. 2021; 10: 98. DOI: 10.30699/fhi.v10i1.332

\section{INTRODUCTION}

The outbreak of coronavirus started from Wuhan, China, in December 2019 soon became a pandemic worldwide. COVID-19 pandemic has challenged the world healthcare systems due to the large number of people affected. In this regard, due to the large number of people with COVID 19 being referred to hospitals and medical centers, the authorities soon concluded that the available facilities could not meet the needs of this pandemic [1]. So, different countries have sought to use innovative methods to fight against the COVID 19 virus. The main challenges for the healthcare systems were the large number of patients with the virus who could be cared for at home, the lack of medical staff especially doctors and nurses, the lack of facilities in intensive care units, and the general lack of hospital beds [2]. Therefore, some novel methods were proposed, of which one of the creative ways to control the COVID 19 pandemic is tele-nursing. Tele-nursing is a nurse-client communication model, which was firstly proposed by Peplau, a nursing theorist, in 1952 []. Tele-nursing seems to be a new opportunity in the COVID-19 pandemic, emphasizing on education and self-care, overcoming issues such as limitations of hospital beds and nursing staff, and reducing the treatment costs and disease transition. As well, patient's education is a vital strategy as one of the most remarkable nursing roles is to control the disease's 
process and the related complications [3]. Telenursing for controlling the COVID-19 pandemic is a common and practical method, in which technological methods are used with the supervision and patient care in hospitals and the community. Patient's monitoring in the ICU, electronic patient records, and clinical nursing implementation in the community, owing to new technologies, enable telenursing to be considered as an integral part of nursing. Moreover, Tele-nursing is intended to provide, manage, and coordinate patient care with the help of web-based systems. Nurses mostly conduct nursing processes, including assessment, nursing diagnosis, planning, implementation, and evaluation using ICT in nursing sciences [4] Additionally, it was indicated that tele-nursing can significantly change the patient care delivery by "flattening the morbidity and mortality curve" in the COVID-19 pandemics, since it provides healthcare using technological infrastructures in various contexts [4].

The results of some previous studies showed that hospitals suffer from a shortage of nursing staff for patient care. The current models of treatment, care, and disease prevention are not capable of controlling the COVID-19 pandemic because of the high disease's incidence and mortality rates as well as disease transmission to the nursing staff $[\underline{5}, \underline{6}]$.

In some countries, mortality reduced in the shortterm with official forced restrictions, though when returning to normal conditions, the disease emerged again. By passing a few months from the pandemic, most countries in the world have experienced three peaks of COVID-19. Of note, the applications of telenursing also provided many benefits in other diseases. Tele-nursing is performed on web-based software and hardware, which focus on disease prevention and patients' home care. Tele-nursing is a cost-effective method that reduces treatment costs, compensates hospital bed and nursing staff shortage, reduces patient anxiety and quarantine, and keeps the patient at home to avoid infecting others in society. Tele-nursing also reduces the risk of nursing staff infection. As a result, it becomes more costeffective and provides better performance than the existing and traditional methods. The patient's web facilities such as smartphones, computers, tablets, and laptops, help them during this kind of treatment $[\underline{7}, \underline{8}]$.

Implementing tele-nursing, overcoming its challenges, and using their potential capabilities to help patients suffering from COVID 19 require significant resources and endeavors. A promising approach mostly uses information technology (IT) as well as medical care facilities and equipment on the Internet base, which allows the provision of suitable and up-to-date information according to the pandemic conditions with appropriate patients' feedbacks. Many web-based interventions like telenursing have been employed for many years for the treatment of chronic diseases (e.g., diabetes, heart and lung diseases, and tele-nursing recovery period follow-up) in different countries. However, online searches on the telenursing during the COVID-19 pandemic revealed some challenges and capabilities

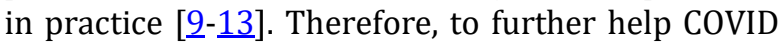
19 patients, the focus is currently on telenursing. This review aimed to identify the challenges and opportunities of tele-nursing in patients suffering from COVID 19 as well as the roles of information technology and web-based technologies in better programing the implementation of tele-nursing by identifying its challenges and capabilities. We conducted this integrative review to identify challenges and capabilities of tele-nursing during the COVID-19 pandemic, and also to identify discrepancies in various studies related to tele nursing. Notably, the integrative review approach is particularly well-suited for reviewing a topic across diverse research designs and methodologies used in order to provide a more comprehensive understanding on the phenomenon under study [11].

This integrative review study, by introducing the challenges and opportunities of tele-nursing, can help patients with COVID 19 to gain better care.

This study question is what are the challenges and opportunities of tele-nursing during the Covid 19 pandemic?

\section{MATERIAL AND METHODS}

This was an integrative study performed on evidence regarding tele-nursing. In addition, this study was conducted based on the Broome method at the following three stages: Literature search, data evaluation, and data analysis. It is noteworthy that an integrative review presents a summary of previous empirical and theoretical studies in order to provide a more comprehensive understanding of the telenursing, and its challenges and opportunities [14]. Tele-nursing was observed in the COVID-19 pandemic, so what are its challenges and opportunities under this condition? To answer this question, the current integrative review was conducted from Dec, 2019 to Jan, 2021. In the present study, we have searched some databases, including PubMed, MEDLINE, Web of Science, Scopus, CINHAL and Google Scholar with keywords COVID-19, Coronavirus, SARS-COV-2, Telenursing, nurse roles, technology, pandemics, internet, and challenges and opportunities using the MeSH terms and OR, AND operators in combination to find more articles from the above-mentioned databases. To fully comply with this integrative review's tele-nursing, a thorough review of the databases was implemented to include all the related eligible articles. 


\section{Search Strings Used in Pubmed}

(Tele nursing [MeSH Terms] AND COVID 19 or SARSCOV-2 or coronavirus [MeSH Terms] [All Fileds]) OR (Tele nursing [MeSH Terms] AND Challenges [subheading] [All Fileds]) OR (Telenursing [MeSH Terms] AND Nursing role [Subheading] [All Fileds]) OR (Tele nursing [MeSH Terms] AND Opportunities [Subheadings] [All Fileds]).

By searching the databases, we found 52 articles and abstracts. The inclusion criteria of this study were the followings: studies on tele-nursing with COVID-19 in the title and text, from the beginning of the COVID-19 pandemic up to now, by focusing on challenges and opportunities of tele-nursing, and published in English. As well, the exclusion criteria were as follows: Tele-nursing for non-COVID-19, text-less studies published in languages other than English, and studies published before the time of the COVID19 pandemic.

The included studies were reviewed at four stages. Firstly, all the 52 complete articles and abstracts were reviewed, and 22 duplicates were then excluded. Next, the articles' titles were reviewed and 10 articles were excluded due to the exclusion criteria. Afterward, abstracts were reviewed and 3 articles were excluded. At the final stage, the articles' texts were reviewed, and nine articles were included at last (Fig 1).

According to the Broome method, for data analysis, the data were extracted from the main sources and then organized into an integrative summary. Thereafter, these were classified and summarized, which finally provided a general error-free interpretation of the main sources as well as an innovative combination of the evidence regarding the objectives of the data analysis phase. After an ono-byone comparison of the extracted data, the similar data were classified, and the classes were then coded and compared with each other. Accordingly, this method includes Data display, Data comparison, Data reduction, conclusion drawing, and Verification [ $\underline{14}$, $\underline{15}]$.

For this purpose, at the analysis stage, the collected information included author's name, publication year, country, type of study, the purpose of the study, and results. This information was collected from all the included articles and then tabulated (Table 1). At the data collection stage, no interpretation was used, and the original terms of the articles used by the author were applied. Finally, two researchers analyzed the results, and in case of any disagreement, an agreement was achieved considering the third researcher's opinion.

All authors approved the internal validity of the article with Cochrane Collaboration High Risk of Bias standards [16]. Of the nine articles, seven articles had at least 'high risk' of bias [다-22, $\underline{4}]$, and two articles had 'low risk' in all domains (study eligibility criteria, identification and selection study, data collection and study appraisal, synthesis and findings) $[\underline{23}, \underline{24}]$.

\section{RESULTS}

\section{Search results}

Details of the processes of article searching and screening are presented in Fig 1. After excluding duplicated articles and those with title-abstract inconsistency, the full-text of 20 relevant studies was evaluated, of which 13 articles did not meet the inclusion criteria. Finally, nine articles were analyzed at this stage.

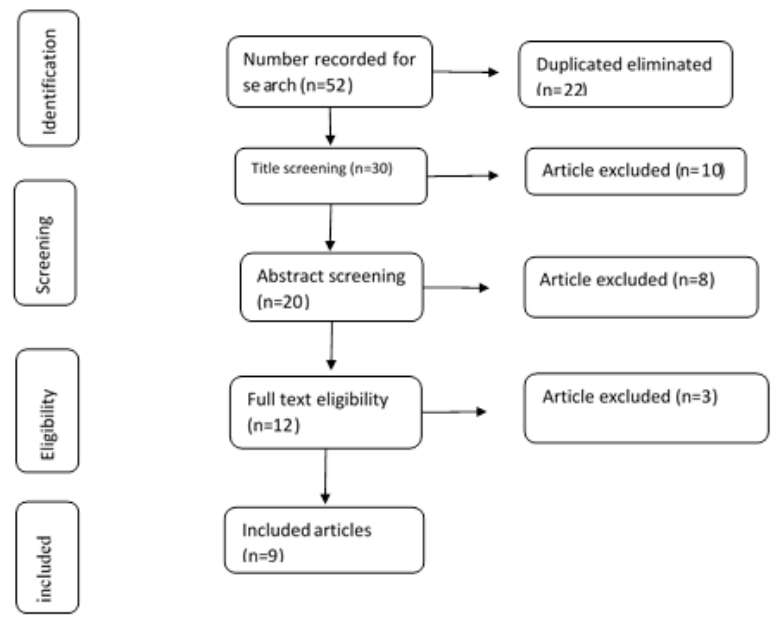

Fig 1: PRISMA flowchart showing the inclusion of papers on integrative review

\section{Characteristics of included studies}

Some general characteristics of these studies are presented in Table 1. The included studies belonged to various journals dating 2020 published in different countries that were involved in the COVID-19 pandemic. Correspondingly, these seven studies have been performed in the United States, Brazil, Thailand, Indonesia, Cyprus, and Iran. The common denominators of these countries were the high incidence rate of COVID 19 and many challenges involved, as well as the use of tele-nursing. Two studies had the original design, while seven studies were short articles such as Editorial, Letter to Editor, and Perspective.

\section{Quality assessment}

This review evaluated 8 studies using the Critical Appraisal Skills Program (CASP checklist). The CASP Checklist was used to inform the quality appraisal of the papers. All studies were comprehensively assessed with regard to both their methodological or theoretical rigor, data relevance, and an overall quality appraisal as 'High quality' or 'low quality' [15].

The quality of one of the evaluated articles was 
generally high. The other 7 articles did not meet the evaluation criteria due to the type of study. No study was excluded based on the level of evidence or quality assessment. Finally, the obtained results were presented in the following two main themes: challenges and opportunities.

Table 1: Characteristics of included studies

\begin{tabular}{|c|c|c|c|c|}
\hline Author /Year/ Country & Title & $\begin{array}{l}\text { Type of } \\
\text { article }\end{array}$ & Objective & Key outcomes \\
\hline Schaumberg/2020/US & $\begin{array}{l}\text { Advanced Practice } \\
\text { Telenursing } \\
\text { Through a } \\
\text { Pandemic }\end{array}$ & Commentary & $\begin{array}{l}\text { brief description of the } \\
\text { procedure, self-reflection } \\
\text { of the therapeutic } \\
\text { relationships during my } \\
\text { TN } \\
\text { experience, and } \\
\text { recommendations for } \\
\text { nurses interested in TN }\end{array}$ & $\begin{array}{l}\text { Implementation and licensing } \\
\text { requirements, insurance coverage of } \\
\text { the care services, coordination with } \\
\text { other units such as hospitals, } \\
\text { laboratories, and radiology, } \\
\text { hardware and software } \\
\text { infrastructures. Reduce stress and } \\
\text { anxiety in quarantined patients, IT } \\
\text { advancement, providing the hope } \\
\text { for the quarantined patient to the } \\
\text { medical staff. }\end{array}$ \\
\hline Caetano et al/ 2020/Brazil & $\begin{array}{l}\text { Challenges and } \\
\text { opportunities for } \\
\text { telehealth during } \\
\text { the COVID-19 } \\
\text { pandemic: ideas on } \\
\text { spaces and } \\
\text { initiatives in the } \\
\text { Brazilian context }\end{array}$ & Essay & $\begin{array}{l}\text { discuss the spaces for } \\
\text { telehealth's contribution } \\
\text { to dealing with the } \\
\text { COVID-19 epidemic }\end{array}$ & $\begin{array}{l}\text { Implementation and licensing } \\
\text { requirements, insurance coverage of } \\
\text { the care services, coordination with } \\
\text { other units such as hospitals, } \\
\text { laboratories, and radiology, } \\
\text { hardware and software } \\
\text { infrastructures. Development of } \\
\text { nursing knowledge, the appearance } \\
\text { of technological care, educating } \\
\text { caregivers using patient technologic } \\
\text { devices including smartphones, } \\
\text { computers. }\end{array}$ \\
\hline Rakhmawati/2020/Indonesia & $\begin{array}{l}\text { IS telenursing a } \\
\text { solution for } \\
\text { managing the } \\
\text { impact of covid-19 } \\
\text { on the mental } \\
\text { health of school- } \\
\text { aged children? }\end{array}$ & Perspective & $\begin{array}{l}\text { Telenursing A Solution for } \\
\text { Managing the Impact of } \\
\text { Covid-19 On the Mental } \\
\text { Health of School-Aged } \\
\text { Children }\end{array}$ & $\begin{array}{l}\text { lack of special protocols, } \\
\text { coordination with other engaged } \\
\text { units such as hospitals, laboratories, } \\
\text { and radiology facilities, hardware } \\
\text { and software infrastructures, the } \\
\text { patient-nurse gap }\end{array}$ \\
\hline Atashi et al/2020/Iran & $\begin{array}{l}\text { Challenges of } \\
\text { Home Health Care } \\
\text { During COVID-19 } \\
\text { Outbreak in Iran }\end{array}$ & $\begin{array}{l}\text { Letter to } \\
\text { Editor }\end{array}$ & $\begin{array}{l}\text { Explore challenges of } \\
\text { home health care during } \\
\text { covid-19 outbreak }\end{array}$ & $\begin{array}{l}\text { Possibility for frequent contact } \\
\text { between the nurses and patients, } \\
\text { better management of the } \\
\text { outbreaks. Development of nursing } \\
\text { knowledge, the appearance of } \\
\text { technological care, compensating } \\
\text { the lack of health care staff and } \\
\text { equipment, reduce stress and } \\
\text { anxiety in quarantined patients } \\
\text { meeting patient's educational, } \\
\text { nutritional, caring and counseling } \\
\text { needs, educating caregivers using } \\
\text { patient technologic devices } \\
\text { including smartphones, computers }\end{array}$ \\
\hline Asimakopoulou/2020/Cyprus & $\begin{array}{l}\text { Telenursing in } \\
\text { Clinical Practice } \\
\text { and Education }\end{array}$ & Editorial & $\begin{array}{l}\text { The survey of use } \\
\text { telenursing in clinical } \\
\text { practice and education }\end{array}$ & $\begin{array}{l}\text { Patient's information confidentiality } \\
\text { and security, lack of special } \\
\text { protocols the questioning of real } \\
\text { nursing, the nursing skills decline, } \\
\text { the integration of traditional and } \\
\text { scientific care. IT advancement, } \\
\text { providing the hope for the } \\
\text { quarantined patient to the medical } \\
\text { staff meeting patient's educational, } \\
\text { nutritional, caring and counseling } \\
\text { needs, educating caregivers using } \\
\text { patient technologic devices } \\
\text { including smartphones, computers. }\end{array}$ \\
\hline $\begin{array}{l}\text { Purabdollah and } \\
\text { Ghasempour/2020/Iran }\end{array}$ & $\begin{array}{l}\text { Tele-Nursing New } \\
\text { Opportunity for } \\
\text { Nursing Care in } \\
\text { COVID-19 } \\
\text { Pandemic Crisis }\end{array}$ & $\begin{array}{l}\text { Letter to the } \\
\text { Editor }\end{array}$ & $\begin{array}{l}\text { Tele-nursing aimed to } \\
\text { improve quality of care, } \\
\text { patient safety, and quick } \\
\text { access to nursing care by } \\
\text { overcoming geographical } \\
\text { barriers. }\end{array}$ & $\begin{array}{l}\text { Educational needs regarding } \\
\text { adherence to drug treatment, drug } \\
\text { side effects, diet, mental counseling, } \\
\text { observance of standards of care, } \\
\text { health care and follow-up of disease } \\
\text { outcomes helped through tele- } \\
\text { nursing. IT advancement, providing }\end{array}$ \\
\hline
\end{tabular}




\begin{tabular}{|c|c|c|c|c|}
\hline Author /Year/ Country & Title & $\begin{array}{l}\text { Type of } \\
\text { article }\end{array}$ & Objective & Key outcomes \\
\hline & & & & $\begin{array}{l}\text { the hope for the quarantined patient } \\
\text { to the medical staff meeting } \\
\text { patient's educational, nutritional, } \\
\text { caring and counseling needs, } \\
\text { educating caregivers using patient } \\
\text { technologic devices including } \\
\text { smartphones, computers }\end{array}$ \\
\hline Chakeri et al/2020/Iran & $\begin{array}{l}\text { Evaluating the } \\
\text { effect of nurse-led } \\
\text { telephone } \\
\text { follow-ups } \\
\text { (tele-nursing) on } \\
\text { the anxiety levels } \\
\text { in people with } \\
\text { coronavirus }\end{array}$ & $\begin{array}{l}\text { Original } \\
\text { Article }\end{array}$ & $\begin{array}{l}\text { determine the effect of } \\
\text { nurse-led telephone } \\
\text { follow-ups (tele-nursing) } \\
\text { on the level of anxiety of } \\
\text { people with coronavirus }\end{array}$ & $\begin{array}{l}\text { the appearance of technological } \\
\text { care, reduce stress and anxiety in } \\
\text { quarantined patients, reduced } \\
\text { mortality and control the cycle of } \\
\text { disease transmission, reduce the } \\
\text { costs of patient and health care } \\
\text { system, while emphasizing patient's } \\
\text { independence }\end{array}$ \\
\hline $\begin{array}{l}\text { Gunawan \& } \\
\text { Aungsuroch/2020/Thailand }\end{array}$ & $\begin{array}{l}\text { 'New Normal' in } \\
\text { Covid-19 Era: A } \\
\text { Nursing } \\
\text { Perspective from } \\
\text { Thailand }\end{array}$ & $\begin{array}{l}\text { Letter to the } \\
\text { Editor }\end{array}$ & $\begin{array}{l}\text { Explore Nursing } \\
\text { Perspective from COVID } \\
19\end{array}$ & $\begin{array}{l}\text { The patient-nurse gap, the } \\
\text { questioning of real nursing, the } \\
\text { nursing skills decline, the } \\
\text { integration of traditional and } \\
\text { scientific care, the teamwork } \\
\text { damage, and the change in the role } \\
\text { of nurses. the appearance of } \\
\text { technological care, reduces stress } \\
\text { and anxiety in quarantined patients } \\
\text { reduced mortality and control the } \\
\text { cycle of disease transmission, } \\
\text { reduce the costs of patient and } \\
\text { health care system while } \\
\text { emphasizing patient's independence }\end{array}$ \\
\hline Arneson et al/2020/US & $\begin{array}{l}\text { Answering the } \\
\text { Call: Impact of } \\
\text { Tele-ICU Nurses } \\
\text { During the COVID- } \\
19 \text { Pandemic }\end{array}$ & $\begin{array}{l}\text { Research } \\
\text { article }\end{array}$ & $\begin{array}{l}\text { To describe how the } \\
\text { skilled tele-intensive care } \\
\text { unit nurses in our health } \\
\text { system quickly changed } \\
\text { from a patient-focused } \\
\text { strategy to a clinician- } \\
\text { focused approach during } \\
\text { the coronavirus disease } \\
2019 \text { crisis. }\end{array}$ & $\begin{array}{l}\text { Provided clinical knowledge for } \\
\text { nurses, expanded critical care units. } \\
\text { Using technology, virtual rounding, } \\
\text { and increased collaboration with } \\
\text { nurses, tele-intensive care unit } \\
\text { nursing minimized the risk to } \\
\text { bedside nurses while maintaining a } \\
\text { high level of care for patients }\end{array}$ \\
\hline
\end{tabular}

\section{The challenges include the following subcategory}

Problems with implementation and licensing requirements $[\underline{17}, \underline{18}]$, insurance coverage of the care services [17, 18], patient's information confidentiality and security, lack of special protocols $[\underline{19}, \underline{4}]$, coordination with other engaged units such as hospitals, laboratories, and radiology facilities, hardware and software infrastructures [17-19], the patient-nurse gap [ $\underline{19}, \underline{22}]$, the teamwork damage, and the change in the role of nurses [22].

\section{The opportunities include the following} subcategory

Development of nursing knowledge [18, 20-24], the appearance of technological care $[\underline{18}, \underline{20}-24]$, compensating the lack of health care staff and equipment $[\underline{20}, \underline{22}]$, reductions of stress and anxiety in quarantined patients $[\underline{17}, \underline{20}, \underline{23}]$, providing the hope for the quarantined patient to the medical staff $[\underline{17}, \underline{4}]$, while emphasizing on patient's independence [23], meeting patient's educational, nutritional, caring and counseling needs $[\underline{4}, \underline{20}-\underline{22}]$.

\section{DISCUSSION}

Based on the purpose and study question, which was determining the challenges and capabilities of the use of tele-nursing during the COVID 19 pandemic, the study discussion was formed in the two main themes as follows: challenges and capabilities.

Given that the included studies were reviewed, they were not studying that used telenursing against COVID 19 to identify real challenges. As well, most of the challenges and capabilities were derived from the experiences of the authors of the articles. Accordingly, these mentioned challenges and capabilities extracted from the reviewed articles, will consequently help to better implement tele-nursing against COVID 19.

In this regard, the results of a study showed that although tele-nursing inherently is a good method and can help in improving the health status of patients, in the case of patients with COVID 19, because patients are not willing to follow the quarantine protocols, it may not be applicable in all 
areas; however, the use of tele-nursing will be effective [25]. Nurses also use verbal and non-verbal communications, including physical touch, eye contact, gestures, silence, and facial expressions, in caring for patients. Moreover, these behaviors such as expressing empathy, facilitating active listening, and enhancing understanding, contribute into mutual respect between the patient and the nurse. In applying tele-nursing using technology, the concept of care may change and virtual conversation may prevail over face-to-face interactions, which is considered as a challenge [20]. The results of another study showed that teleworking requires some features such as a digital stethoscope used to listen to the sound of the lungs and heart; a web-based camera to see the ear, throat, and skin; and a device used to measure body temperature with having no direct contact with the patient. In addition, a secure electronic medical record that holds all patients' data is needed, and it is important to maintain its safety in order to keep patients' information confidential. It is also important to coordinate the use of this technology under android or IOS, hospital websites, and other applications to provide tele-nursing services for fighting against COVID-19. Even discussing security and meeting facilities in all regions of a country are important challenges [26]. Furthermore, another challenge is obtaining a license to provide tele-nursing activities to patients. As well, paying for tele-nursing recipients is another problem, because patients' visits are virtual and must be defined for insurers to cover services [27].

The results of another study showed that limited access to the Internet or devices such as smartphones, tablets or computers, as well as unfamiliarity with technology may be potential barriers for some patients. In addition, virtual visits for some patients may not be accompanied by examinations performed in face-to-face interviews or diagnostic tests, so their accuracy may pose a challenge to patients and therapists [28]. Advances in technology have changed the roles of nurses, which is also considered as a challenge for tele-nursing. If nurses can solve this challenge by using creative methods and tele-nursing to provide remote nursing care with supervision, patient's education, patient status monitoring, data collection and remote interventions, and Pain management, they can support the patient's family to compensate [29, $\underline{30}]$.

Another theme of this study was the capabilities of tele-nursing. This shows that positive dimensions also exist in the implementation of tele-nursing. In this regard, the results of a previous study showed that nursing staff in the current situation of working in intensive care units caring for patients with Covid19 , are mostly faced with a lack of personal protective equipment and hospital beds in some countries. The implementation of tele-nursing helps in eliminating these shortcomings [31]. Additionally, another study showed that patients with COVID-19 who are in quarantine, mainly suffer from psychological problems due to loneliness and death anxiety, and tele-nursing plays an effective role in reducing these complications [32]. Another issue in the implementation of tele-nursing is targeting the geographical distance of health care users from the same health care services. Many people infected with Covid 19 live on the borders of towns or villages with no access to adequate medical care. By removing these barriers, Tele-Nursing helps patients to better fight against COVID 19. In addition, it prevents the spread of disease and can also be effective on reducing mortality and helping to identify critically ill patients [프. In line with the capabilities of telenursing, it is possible to educate the patient with no time and space restrictions by performing telenursing. This will consequently reduce patients' costs and improve the quality of nursing care. As well, after the patient's discharging from the hospital, the continuity of care is maintained and the patient's recovery and convalescence periods would pass faster [34] .

Nicol et al. 2020 demonstrated that some high-risk groups do not need to go to the emergency zones by receiving tele-nursing services, and avoid the risk of transmitting the infection by visiting and caring at home. Tele-nursing also gives the patient psychological peace, which helps them to be healed more easily in case of illness. Accordingly, it also prevents nosocomial infections [35].

According to the practical implementation of telenursing for cardiovascular patients [ㅌ] , blood sugar control in diabetic patients [글, lung cancer patients in Turkey [요], congestive heart failure patients [10], complications in control of patients undergoing chemotherapy [39], patients discharged due to hypertension [9], and those with various other diseases, despite facing many challenges and problems, these have been found to be successful and have had several effective results. So, this can also bring effective results during the COVID 19 pandemic.

\section{CONCLUSION}

This review is a comprehensive review of the existing articles on COVID 19, which examines the challenges and opportunities of tele-nursing. Since, there is no effective preventive or therapeutic available method for COVID 19 and many people are infected every day all over the world, tele-nursing serves as a creative method which may greatly help the COVID 19 pandemic. Due to the fact that Tele-nursing indicates the important challenges of COVID-19 for both the community and healthcare systems, it also supports the healthcare systems and hospitals. Health care staffs are the main resources in the first line of defense against COVID 19. There for, it is important to prevent them from getting infected and to 
compensate for the shortage of hospital beds. More addition, Tele-nursing reduces treatment costs for patients infected with COVID-19, minimizes the risk of COVID outbreaks and ultimately provides ongoing care for the community. According to the findings of this review study, health policy makers, physicians and patients are strongly advised to use tele-nursing as a suitable option to prevent and control COVID infection, given the extent of the mobile network and the Internet in countries.

\section{Limitations}

This integrative review also had few limitations, including the language of published articles. In this regard, the articles included in this study were published in English, while there may be valuable articles published in other languages that were left out of reach. As well, due to the novelty of the current COVID-19 pandemic, original articles are limited in this regard, and inevitably other articles were used in this study. Moreover, our search covered a limited number of databases; inadequate articles were available in this field that was duplicated in different

\section{REFERENCES}

1. Huang C, Wang Y, Li X, Ren L, Zhao J, Hu Y, et al. Clinical features of patients infected with 2019 novel coronavirus in Wuhan, China. The lancet. 2020; 395(10223): 497-506.

2. Liao X, Wang B, Kang Y. Novel coronavirus infection during the 2019-2020 epidemic: Preparing intensive care units; The experience in Sichuan Province, China. Intensive Care Med. 2020; 46(2): 357-60. PMID: 32025779 Doi:10.1007/s00134-020-05954-2 [PubMed]

3. Christoforou EG, Avgousti S, Ramdani N, Novales C, Panayides AS. The upcoming role for nursing and assistive robotics: Opportunities and challenges ahead. Front Digit Health. 2020; 2: 585656. PMID: $34713058 \quad$ DOI: $\quad 10.3389 /$ fdgth.2020.585656 [PubMed]

4. Asimakopoulou E. Telenursing in clinical practise and education. International Journal of Caring Sciences. 2020; 13(2): 781-2.

5. Rezaie F, Firouzkouhi M, Abdollahimohammad A, Naderifar M. Comparing the effect of education through SMS with face-to-face method on awareness and care in mothers with premature neonates. Medical Science. 2019; 23(98): 540-6.

6. Liu S, Yang L, Zhang C, Xiang YT, Liu Z, Hu S, et al. Online mental health services in China during the COVID-19 outbreak. Lancet Psychiatry. 2020; 7(4): e17-8. PMID: 32085841 DOI: 10.1016/S22150366(20)30077-8 [ubMed]

7. Wu Z, McGoogan JM. Characteristics of and important lessons from the coronavirus disease 2019 (COVID19) outbreak in China: Summary of a report of 72314 databases.

\section{ACKNOWLEDGEMENT}

This study is dedicated to the nurses who participated in the front line of the battle with COVID 19 and became ill and even lost their lives. Their memory will remain in the minds of the world for many years.

\section{AUTHOR'S CONTRIBUTION}

All authors contributed to the literature review, design, data collection and analysis, drafting the manuscript, read and approved the final manuscript.

\section{CONFLICTS OF INTEREST}

The authors declare no conflicts of interest regarding the publication of this study.

\section{FINANCIAL DISCLOSURE}

No financial interests related to the material of this manuscript have been declared.

cases from the Chinese center for disease control and prevention. Jama. 2020; 323(13): 1239-42. PMID: 32091533 Doi:10.1001/jama.2020.2648 [PubMed]

8. Ye J. The role of health technology and informatics in a global public health emergency: Practices and implications from the COVID-19 pandemic. JMIR Med Inform. 2020; 8(7): e19866. PMID: 32568725 DOI: 10.2196/19866 [PubMed]

9. Keshavaraz N, Naderifar M, Firouzkohi M, Abdollahimohammad A, Akbarizadeh MR. Effect of telenursing on the self-efficacy of patients with myocardial infarction: A quasi-experimental study. Signa Vitae. 2020; 16(2): 92-6.

10. França AC, Rodrigues AB, Aguiar MI, Silva RA, Freitas FM, Melo GA. Telenursing for the control of chemotherapy-induced nausea and vomiting: A randomized clinical trial. Texto Contexto Enferm. 2019; 28: 1-15.

11. Esmaeilpour-BandBoni M, Gholami-Shilsar F, Khanaki $\mathrm{K}$. The effects of telephone-based telenursing on glycated hemoglobin among older adults with type 2 diabetes mellitus: A randomized controlled trial. Journal for Nurse Practitioners. 2021; 17(3): 305-9.

12. Fallahpour S, Nasiri M, Fotokian Z, Jannat Alipoor Z, Hajiahmadi M. The effects of telephone-based telenursing on perceived stressors among older adults receiving hemodialysis. Nursing and Midwifery Studies. 2020; 9(4): 201-7.

13. Gavan G, Firouzkouhi M, Abdollahimohammad A, Rahdar Z. Comparison of the effect of SMS training and on-the-job training on adherence to the drug regimen in chemotherapy patients referred to Zabol chemotherapy center in 2018. Journal of Advanced Pharmacy Education \& Research. 2019; 9(S2): 125-9. 
14. Broome ME. Integrative literature reviews for the development of concepts. In: Rodgers BL, Knafl KA (Eds). Concept development in nursing: Foundations, techniques and applications. W. B. Saunders Company, Philadelphia; 2000.

15. Whittemore $\mathrm{R}$, Knafl $\mathrm{K}$. The integrative review: updated methodology. J Adv Nurs. 2005; 52(5): 54653. PMID: 16268861 Doi:10.1111/j.1365-2648.2005. 03621.x [PubMed]

16. Armijo-Olivo S, Ospina M, da Costa BR, Egger M, Saltaji $\mathrm{H}$, Fuentes J, et al. Poor reliability between Cochrane reviewers and blinded external reviewers when applying the Cochrane risk of bias tool in physical therapy trials. PloS one. 2014; 9(5): e96920. PMID: 24824199 Doi: 10.1371/journal.pone.0096920 [PubMed]

17. Schaumberg L. Advanced practice telenursing through a pandemic. J Psychosoc Nurs Ment Health Serv. 2020; 58(9): 4-6. PMID: 32609860 Doi:10.3928/02793695-20200624-09 [ubMed]

18. Caetano R, Silva AB, Guedes AC, Paiva CC, Ribeiro GD, Santos DL, et al. Challenges and opportunities for telehealth during the COVID-19 pandemic: ideas on spaces and initiatives in the Brazilian context. Cad Saúde Pública. 2020; 36: e00088920. PMID: $32490913 \quad$ Doi:10.1590/0102-311X00088920 [PubMed]

19. Rakhmawati W. Is telenursing a solution for managing the impact of COVID-19 on the mental health of school-aged children? Belitung Nursing Journal, 2020; 6(5): 182-4.

20. Atashi A, Nejatian A. Challenges of Home Health Care During COVID-19 Outbreak in Iran. Int J Community Based Nurs Midwifery. 2020; 8(4): 360-1. PMID: 33178859 Doi:10.30476/ijcbnm.2020.86511.1349 [PubMed]

21. Purabdollah M, Ghasempour M. Tele-nursing new opportunity for nursing care in COVID-19 pandemic crisis. Iran J Public Health. 2020; 49(1): 130-1. PMID: $34268221 \quad$ DOI: $\quad 10.18502 /$ ijph.v49iS1.3685 [PubMed]

22. Resnick B. What have we learned about nursing from the Coronavirus pandemic? J Am Med Dir Assoc. 2020; 21(7): 997-8. PMID: 32674836 Doi: 10.1016/j.jamda.2020.06.007 [PubMed]

23. Chakeri A, Jalali E, Ghadi MR, Mohamadi M. Evaluating the effect of nurse-led telephone follow-ups (telenursing) on the anxiety levels in people with coronavirus. J Family Med Prim Care. 2020; 9(10): 5351-4. PMID: 33409214 Doi: 10.4103/jfmpc.jfmpc_847_20 [․ㅏuMed]

24. Arneson SL, Tucker SJ, Mercier M, Singh J. Answering the call: Impact of tele-ICU nurses during the COVID19 pandemic. Crit Care Nurse. 2020; 40(4): 25-31. PMID: $\quad 32464662 \quad$ Doi:10.4037/ccn2020126 [PubMed]

25. Wright $\mathrm{CH}$, Wright J, Shammassian B. COVID-19: Launching neurosurgery into the era of telehealth in the United States. World Neurosurg. 2020; 140: 54-5. PMID: 32422330 Doi: 10.1016/j.wneu.2020.05.092

\section{[PubMed]}

26. Gunawan J, Aungsuroch Y, Marzilli C. 'New Normal' in COVID-19 era: A nursing perspective from Thailand. J Am Med Dir Assoc. 2020; 21(10): 1514-5. PMID: $32859516 \quad$ Doi: $10.1016 / j$ j.jamda.2020.07.021 [PubMed]

27. Moreland A, Herlihy C, Tynan MA, Sunshine G, McCord $\mathrm{RF}$, Hilton $\mathrm{C}$, et al. Timing of state and territorial COVID-19 stay-at-home orders and changes in population movement: United States, March 1-May 31, 2020. MMWR Morb Mortal Wkly Rep. 2020; 69(35): 1198-1203. PMID: 32881851 DOI: 10.15585/mmwr.mm6935a2 [PubMed]

28. Reed ME, Huang J, Graetz I, Lee C, Muelly E, Kennedy $C$, et al. Patient characteristics associated with choosing a telemedicine visit vs office visit with the same primary care clinicians. JAMA Netw Open. 2020: 3(6): $\quad$ e205873. 32585018 Doi:10.1001/jamanetworkopen.2020.5873 [PubMed]

29. Liu X, Na RS, Bi ZQ. Challenges to prevent and control the outbreak of novel coronavirus pneumonia (COVID-19). Zhonghua Liu Xing Bing Xue Za Zhi. 2020; 41: E029. PMID: 32220275 Doi:10.3760/cma.j.cn112338-20200216-00108 [PubMed]

30. Bashir A, Bastola DR. Perspectives of nurses toward telehealth efficacy and quality of health care: Pilot study. JMIR Med Inform. 2018; 6(2): e35. PMID: 29802089 Doi:10.2196/medinform.9080 [PubMed]

31. Şat SÖ, Sözbir ŞY. Use of mobile applications by pregnant women and levels of pregnancy distress during the COVID-19 (Coronavirus) pandemic. Matern Child Health J. 2021; 25(7): 1057-68. PMID: 33929653 [PubMed]

Doi:10.1007/s10995-021-03162-y

32. Zhou $\mathrm{X}$, Snoswell CL, Harding LE, Bambling $\mathrm{M}$, Edirippulige S, Bai $X$, et al. The role of telehealth in reducing the mental health burden from COVID-19. Telemed J E Health. 2020; 26(4): 377-9. PMID: 32202977 Doi:10.1089/tmj.2020.0068 [PubMed]

33. Arabi YM, Azoulay E, Al-Dorzi HM, Phua J, Salluh J, Binnie A, et al. How the COVID-19 pandemic will change the future of critical care. Intensive Care Med 2021: 47(3): 282-91. PMID: 33616696 DOI: 10.1007/s00134-021-06352-y [PubMed]

34. Bajema KL, Oster AM, McGovern OL, Lindstrom S, Stenger MR, Anderson TC, et al. Persons evaluated for 2019 novel coronavirus: United States, January 2020. MMWR Morb Mortal Wkly Rep. 2020; 69(6): 166-70. PMID: 32053579 Doi:10.15585/mmwr.mm6906e1 [PubMed]

35. Nicol GE, Piccirillo JF, Mulsant BH, Lenze EJ. Action at a distance: Geriatric research during a pandemic. J Am Geriatr Soc. 2020; 68(5): 922-5. PMID: 32207542 Doi:10.1111/jgs.16443 [PubMed]

36. Elgaphar SMA, El Gafar SIA. Effect of tele-nursing (phone-based follow-ups) on self-efficacy, healthy lifestyle, and glycemic control in diabetic patients. IOSR Journal of Nursing and Health Science. 2017; 


\section{6(3): 67-76.}

37. Hintistan S, Nural N, Cilingir D, Gursoy A. Therapeutic effects of nurse telephone follow-up for lung cancer patients in Turkey. Cancer Nurs. 2017; 40(6): 508-16. PMID:

27977427

Doi:10.1097/NCC.0000000000000461 [ubMed]

38. Piscesiana E, Afriyani T. The effect of tele-nursing on preventing re-admission among patients with heart failure: A literature review. International Journal of Nursing and Health Services. 2020; 3(2): 251-60.

39. Sato D. Effectiveness of Telenursing for Postoperative Complications in Patients with Prostate Cancer. Asia Pac J Oncol Nurs. 2020; 7(4): 396-403. PMID: 33062837 Doi: 10.4103/apjon.apjon_28_20 [PubMed] 